\title{
Bed stress assessment under solitary wave run-up
}

\author{
Mohammad Bagus Adityawan ${ }^{1}$ and Hitoshi Tanaka ${ }^{2}$ \\ ${ }^{1}$ Graduate School of Engineering, Tohoku University, 6-6-06 Aoba Aramaki, Sendai 980-8579, Japan \\ ${ }^{2}$ Department of Civil Engineering, Tohoku University, 6-6-06 Aoba Aramaki, Sendai 980-8579, Japan
}

(Received October 31, 2010; Revised February 14, 2011; Accepted February 21, 2011; Online published October 24, 2012)

\begin{abstract}
Understanding and forecasting tsunami wave run-up is very important in mitigating tsunami hazards. The bed stress under wave motion governs viscous wave damping and sediment transport processes, which change coastal morphology. One of the most common methods used for simulation is the shallow water equation (SWE) model, often used with a Manning-style approach for modeling bottom friction. Boundary-layer approaches provide better information regarding bed stress, particularly since they are also valid for nonsteady flows. In this study, a simulation of wave run-up is carried out by simultaneous coupling of the SWE model with the $k-\omega$ model. The $k-\omega$ model is used near the flow boundary at the bottom, only for assessing the boundary layer shear stress. Free stream velocity and calculations of the free surface evolution are obtained from the SWE model. Both this method, and the conventional method, are applied to the canonical problem of a solitary wave propagating over a constant depth and then up a sloping beach (Synolakis, 1987). The new method is found to increase the computational accuracy and physical realism compared to the conventional Manning method. Comparison of bed shear stresses shows that the new method is able to accommodate the effect of deceleration, which leads to sign changes and a phase shift between the free stream velocity and the bed stress. Furthermore, it is found that during the run-up and run-down process, bed stress in the direction of leaving the shoreline is more dominant.
\end{abstract}

Key words: Wave run-up, numerical simulation, shallow water equation, boundary layer, bed stress.

\section{Introduction}

The Great Tsunami of 2004 demonstrated the impact of tsunami waves both near and far (Geist et al., 2006). While flooding is a primary concern, tsunami waves cause large amounts of sediment transport, and drastically change the coastal morphology. They are also known to cause erosion, as seen in the East Java tsunami (Tsuji et al., 1995). Sediment transport processes under a wave motion are closely related to the bed shear stress, which is influenced by the boundary layer beneath the wave itself (Vittori and Blondeaux, 2008).

Studies of the evolution of tsunami waves are most often conducted using the long-wave approximation of the governing equations of motion. This study also uses numerical solutions and laboratory experiments. Synolakis (1987) conducted a series of laboratory experiments measuring the run-up of solitary waves. That study had a significant impact in the field, because he also provided analytical results for what he referred to as the canonical problem, i.e., a solitary wave propagating over a constant depth and then running up a sloping beach. His laboratory results are often used as benchmarks for validating numerical models.

There are several types of numerical models for the study of tsunami wave run-up. The SWE model is commonly used in tsunami wave run-up simulation and is known to model tsunami evolution well (Liu et al., 1991) and it is

Copyright (C) The Society of Geomagnetism and Earth, Planetary and Space Sciences (SGEPSS); The Seismological Society of Japan; The Volcanological Society of Japan; The Geodetic Society of Japan; The Japanese Society for Planetary Sciences; TERRAPUB.

doi:10.5047/eps.2011.02.012 known for its computational efficiency, relatively good accuracy, and ease of modifying. Titov and Synolakis (1998) have used the SWE model to model a range of real tsunami inundation, including the 1993 Okushiri tsunami. More recently, Adityawan (2007) applied the SWE model to various cases of wave run up in shallow water, including the inundation of the 2004 tsunami in Banda Aceh, Indonesia. Nevertheless, the SWE model provides few details of the flow near the boundary. Variants of the Boussinesq equation (Boussinesq, 1872; Peregrine, 1967; Madsen and Sørensen, 1992; Nwogu, 1993; Wei and Kirby, 1995) have also been applied to various cases of wave run-up. Such models provide a higher accuracy than the SWE for shorter waves, but require more computation time and are not as flexible as the SWE in the treatment of alternating wet/dry and boundaries. Surprisingly, they have not been demonstrated to provide more accurate run-up predictions for tsunami run-up even for landslide waves (Lynett et al., 2003).

Two-dimensional (one horizontal and one vertical dimension) models have been proposed solving Reynolds Averaged Navier Stokes (RANS) with turbulence closure using a two-equation model, such as given by NEWFLUME (Lin, et al., 1999) or CADMAS SURF (Isobe, et al., 1999). Liu et al. (2005) proposed a full 3-D model using RANS. All such models adopt the VOF method and are able to reproduce the flow behavior in detail. However, they require exceptionally long computation times and are temperamental in terms of stability, and, hence, are so far fairly limited in the application to modeling analytical results or laboratory experiments. Other than possibly the case of landslide generated waves very nearshore, the Boussinesq and RANS 


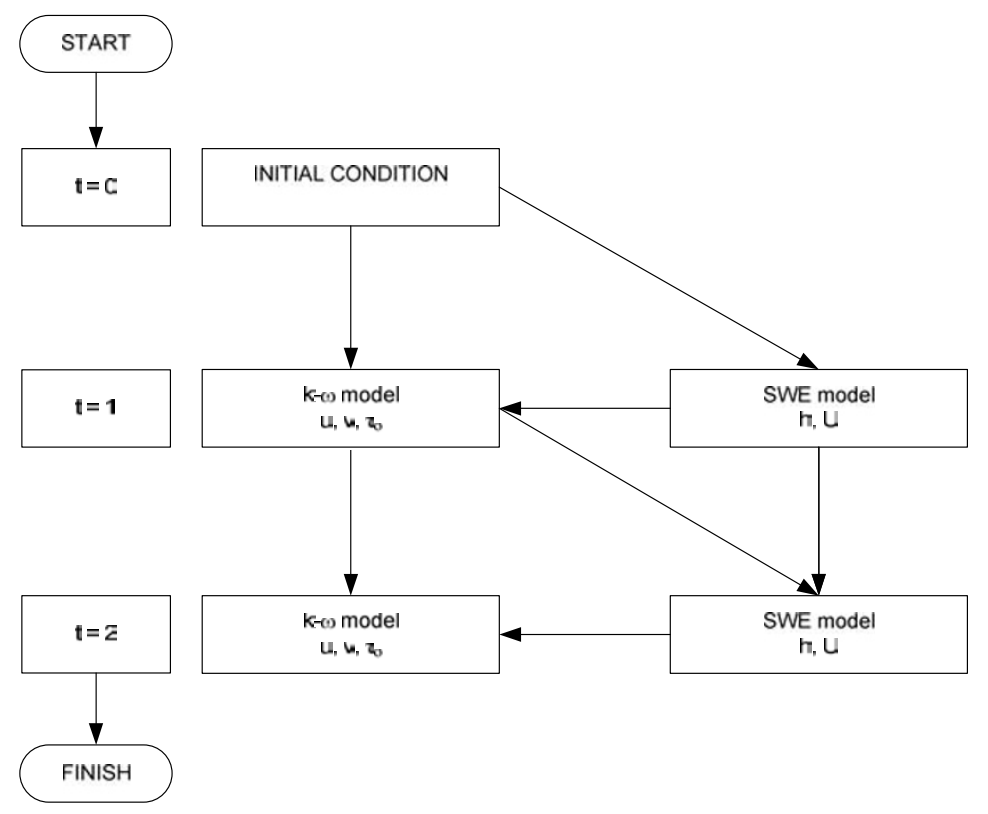

Fig. 1. Computation flow chart.

models do no better in terms of inundation prediction than the SWE model, which enables implementation in practical applications, but is limited in its calculation of bottom shear stresses.

The SWE model consists of two simultaneous equations: conservation of mass (also known as continuity) and conservation of momentum. The empirical method of Manning is commonly used to evaluate bed shear stress. Because it was originally developed for steady river flow, the near-bed flows under wave motion cannot always be explained using the Manning approximation method. In nature, the bed stress changes its sign in a deceleration phase to a direction opposite to the free stream velocity, as shown by Liu et al. (2007). Yet, the Manning method calculates bed stress in the same direction as the velocity. It is clear that, for a detailed analysis, the Manning method is not sufficient.

There have been several studies of bed stress under wave motion. Tanaka (1988) estimated the bottom shear stress under non-linear waves by a modified stream function theory and proposed a formula to predict bed load transport, except near the surf zone in which acceleration effects play an important role. Furthermore, Tanaka and Thu (1994) have shown the importance of friction and phase differences between velocity and bed stress under waves, exactly where the Manning method fails to explain the switch. In general, more complete bed stress formulations may incorporate both velocity- and acceleration-related terms, or may include phase lag (e.g., Kabiling and Sato, 1993; Nielsen, 2002).

Suntoyo and Tanaka have used a boundary-layer approach to assess bed stress under solitary waves. They have demonstrated good accuracy of their bed stress approximation in numerical computations. Two-equation models are often used to assess the boundary-layer properties with $k$ $\epsilon$ and $k-\omega$ being the most common. The $k-\omega$ model has the ability to accommodate the roughness effects as bed boundary conditions and is considered to be more accurate in assessing the boundary-layer properties (Suntoyo, 2006). Adityawan et al. (2009) used a 2D $k-\omega$ model to investigate boundary-layer properties under a periodic sinusoidal wave motion, with good results.

The objective of this study is to assess bed stress under solitary wave run-up using a simultaneous coupling of SWE with a $k-\omega$ model. Each model is benchmarked with reference to a test case. Both models are coupled by replacing the conventional Manning method with a direct assessment of bed stress from the boundary layer using a $k-\omega$ model. Thus, bed stress can be approximated directly from the boundary layer using a $k-\omega$ model. The method is also used to simulate the canonical problem of Synolakis (1987). Further analyses are carried out regarding bed stress assessment.

\section{Model Development \\ 2.1 Coupling method}

The governing equations are SWE and a $k-\omega$ equation. The models are calculated separately at each time step; however, their results are exchanged between the models, enabling a simultaneous calculation. The basic premise for the calculation is to upgrade the SWE model by replacing the Manning terms often used in the SWE using the direct calculation of bed stress in the near bed region using a $k-\omega$ model.

The computation begins with initializing parameters and an initial value of the friction coefficient in the model. The velocity obtained from the SWE model is then applied as the free stream velocity boundary condition in the $k-\omega$ model. Then, the bed stress obtained from the $k-\omega$ model is applied in the momentum equation of the SWE model for the next time step. The process continues until the end of the simulation, as shown in Fig. 1.

A new grid system is developed to allow the simultaneous coupling of both models. The grid system for the method does not require horizontal and vertical grids covering the 


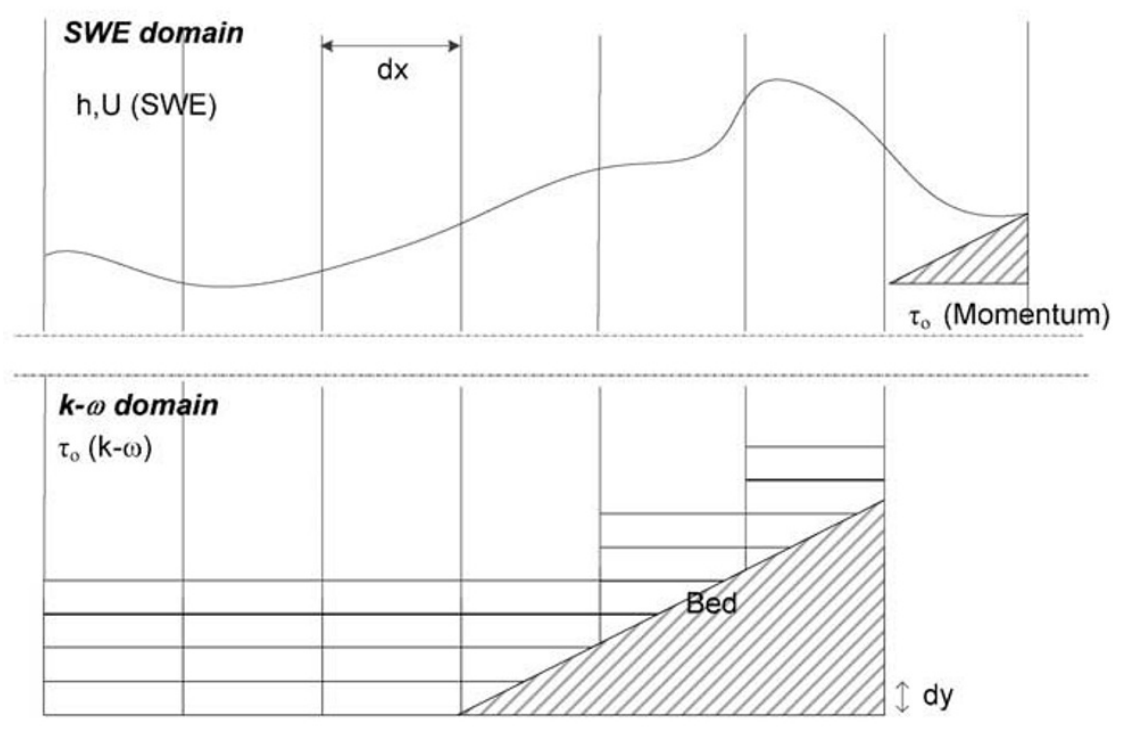

Fig. 2. Domain sketch.

entire domain from bed to the free surface. The vertical grid is only required near the flow bottom boundary to assess the boundary layer for the bed stress calculation. The bottom domain should be at least equal to the boundary-layer thickness. Nevertheless, a multiplication factor of 2 or 3 is advised to ensure that the domain covers the boundary layer. The boundary-layer thickness may be very thin; thus, a small grid size is required. The water depth becomes very thin at the wave front. Therefore, the boundary layer is not accessible anymore. At this location, the bed stress is calculated from the momentum equation in the SWE model, as proposed by Elfrink and Fredsøe (1993). The definition of the model domain and the boundary treatments are shown in Fig. 2.

\subsection{SWE model}

The SWE consists of the continuity equation and the momentum equation as follows:

$$
\begin{gathered}
\frac{\partial h}{\partial t}+\frac{\partial(U h)}{\partial x}=0 \\
\frac{\partial U}{\partial t}+U \frac{\partial U}{\partial x}+g \frac{\partial\left(h+z_{b}\right)}{\partial x}+\frac{\tau_{o}}{\rho h}=0
\end{gathered}
$$

where $h$ is the water-depth, $U$ is the depth averaged velocity, $t$ is time, $g$ is gravity, $z_{b}$ is the bed elevation, $\rho$ is the fluid density and $\tau_{o}$ is the bed stress. The Manning equation is commonly used to assess bed stress. The bed stress relation in the conventional Manning method is assumed to be proportional to the square of the velocity as shown below.

$$
\frac{\tau_{0}}{\rho}=g \times n^{2} \times \frac{U|U|}{R_{h}^{1 / 3}},
$$

where $R_{h}$ is the hydraulic radius, or can be considered to be the water depth for a very wide channel, and $n$ is the Manning roughness.

A wet-dry moving boundary condition is applied in the model to allow run-up simulation. A minimum threshold depth is selected. If the calculated water depth is lower than the threshold, then the water depth and velocity in the corresponding grid is given a zero value (dry cell).

The governing equations are solved using a finitedifference MacCormack predictor-corrector scheme. The predictor step uses a forward difference in space and time. The corrector step uses a backward difference in space and a forward difference in time. The final value is obtained by using a center difference in time from the initial and the corrector value. The method has been applied to solve SWE for various cases (i.e. Adityawan, 2007; Kusuma et al., 2008; Wang et al., 2008). The model also adopts a numerical filter for better stability in calculation. The filter acts as an artificial dissipation. A numerical filter as proposed by Hansen (1962) is used for each time step at each node. The values of depth and velocity are updated applying the following equation:

$$
\begin{aligned}
F(i)= & C \times F(i) \\
& +0.5(1-C)(F(i-1)+F(i+1)) .
\end{aligned}
$$

The $C$ value is set to 0.99 , and $F$ corresponds to the filtered parameters which are the velocity and depth.

\subsection{The $k$ - $\omega$ model}

The governing equation for the $k-\omega$ model is based on the Reynolds-averaged equations of continuity and momentum:

$$
\begin{gathered}
\frac{\partial u_{i}}{\partial x_{i}}=0, \\
\rho \frac{\partial u_{i}}{\partial t}+\rho u_{j} \frac{\partial u_{i}}{\partial x_{j}}=\frac{\partial P}{\partial x_{i}}+\frac{\partial}{\partial x_{i}}\left(2 \mu S_{i j}-\rho \overline{u_{i}^{\prime} u_{j}^{\prime}}\right),
\end{gathered}
$$

where $u_{i}$ and $x_{i}$ denotes the velocity in the boundary layer and location in the grid, $u_{i}^{\prime}$ is the fluctuating velocity in the $x(i=1)$ and $y(i=2)$ directions, $P$ is the static pressure, $v$ is the kinematic viscosity. $\rho \overline{u_{i}^{\prime} u_{j}^{\prime}}$ is the Reynolds stress tensor, and $S_{i j}$ is the strain-rate tensor from the following 


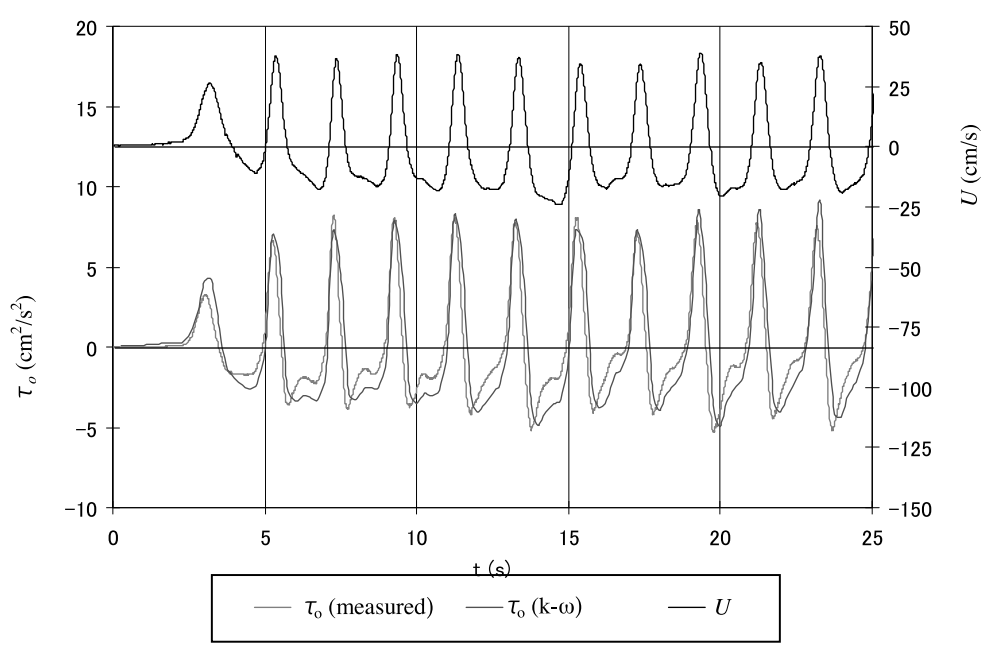

Fig. 3. Bed stress comparison.

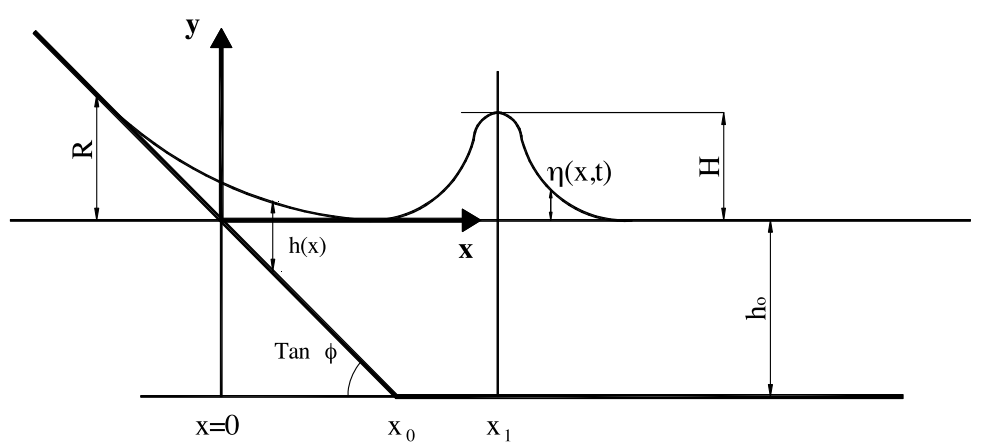

Fig. 4. Solitary wave run-up on a sloping beach.

equation:

$$
S_{i j}=\frac{1}{2}\left(\frac{\partial u_{i}}{\partial x_{j}}+\frac{\partial u_{j}}{\partial x_{i}}\right) .
$$

The Reynolds stress tensor is given through eddy viscosity by a Boussinesq approximation:

$$
-\overline{u_{i}^{\prime} u_{j}^{\prime}}=v_{t}\left(\frac{\partial u_{i}}{\partial x_{j}}+\frac{\partial u_{j}}{\partial x_{i}}\right)-\frac{2}{3} k \delta_{i j},
$$

where $k$ is the turbulent kinetic energy and $\delta_{i j}$ is the Kronecker delta. The turbulent kinetic energy and specific dissipation rate, $\omega$ in the $k-\omega$ model equation, is given as follows:

$$
\begin{aligned}
\frac{\partial k}{\partial t}+u_{j} \frac{\partial k}{\partial x_{j}}= & \tau_{i j} \frac{\partial u_{i}}{\partial x_{j}}-\beta^{*} k \omega \\
& +\frac{\partial}{\partial x_{j}}\left[\left(v+\sigma^{*} v_{t}\right) \frac{\partial k}{\partial x_{j}}\right], \\
\frac{\partial \omega}{\partial t}+u_{j} \frac{\partial \omega}{\partial x_{j}}= & \alpha \frac{\omega}{k} \tau_{i j} \frac{\partial u_{i}}{\partial x_{j}}-\beta \omega^{2} \\
& +\frac{\partial}{\partial x_{j}}\left[\left(v+\sigma v_{t}\right) \frac{\partial \omega}{\partial x_{j}}\right], \\
\tau_{i j}=v_{t}\left(2 S_{i j}\right. & \left.-\frac{2}{3} \frac{\partial u_{k}}{\partial x_{k}} \delta_{i j}\right)-\frac{2}{3} k \delta_{i j}
\end{aligned}
$$

The eddy viscosity is given by

$$
v_{t}=\frac{k}{\omega} .
$$

The values of the closure coefficients are given by Wilcox (1988) as $\beta=3 / 40, \beta^{*}=0.09, \alpha=5 / 9$, and $\sigma=$ $\sigma^{*}=0.5$. The boundary condition at the bottom is no slip boundary. At the free stream, it is assumed that the velocity gradient, the turbulent kinetic energy gradient and the dissipation rate gradient are zero. The governing equations above are solved using a Crank-Nicolson-type implicit finite-difference scheme. More details regarding the scheme implementation can be found in a previous study (Suntoyo et al., 2008).

\section{Numerical Simulation}

The developed method consists of two different models. Each model is verified for an appropriate case. The $k-\omega$ model is used to simulate the bed stress fluctuation under random waves. The SWE model is used to simulate the run-up case.

\section{$3.1 k$ - $\omega$ model verification}

The $k-\omega$ model is verified using measurement data of random waves in a flume. Bed stress measurements were conducted using a hot film sensor. Details of the experiment can be found in a previous study by Tanaka et al. (1998). The data sets consist of free stream velocity and bed stress over time. Bed stress measurements were made using a very thin 


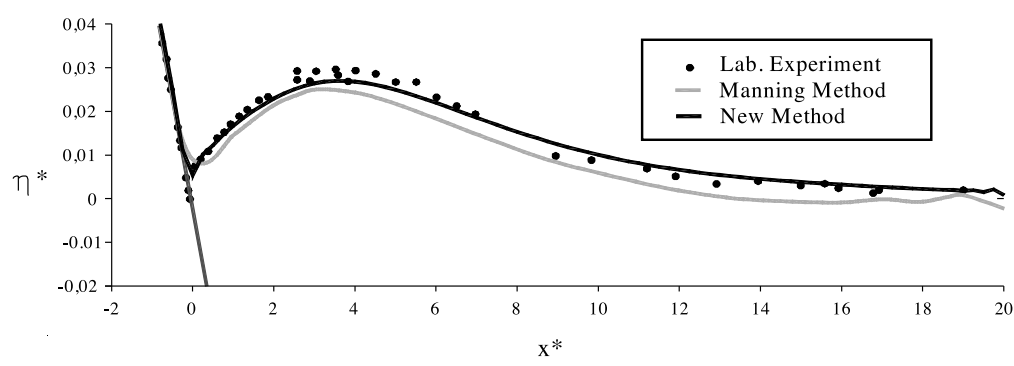

(a) $t^{*}=45$

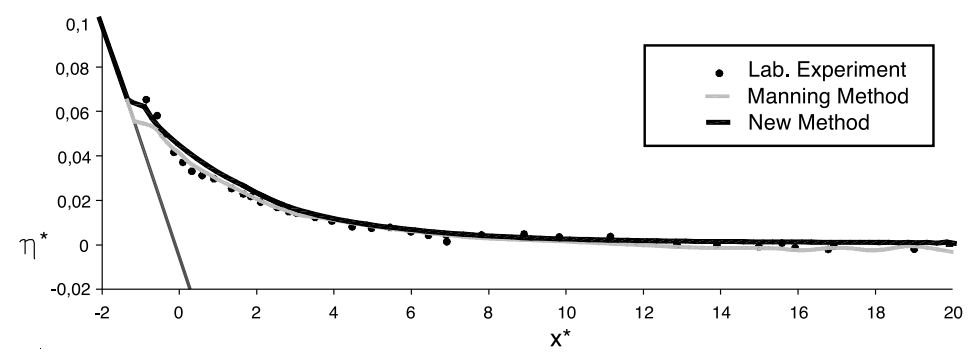

(b) $t^{*}=55$

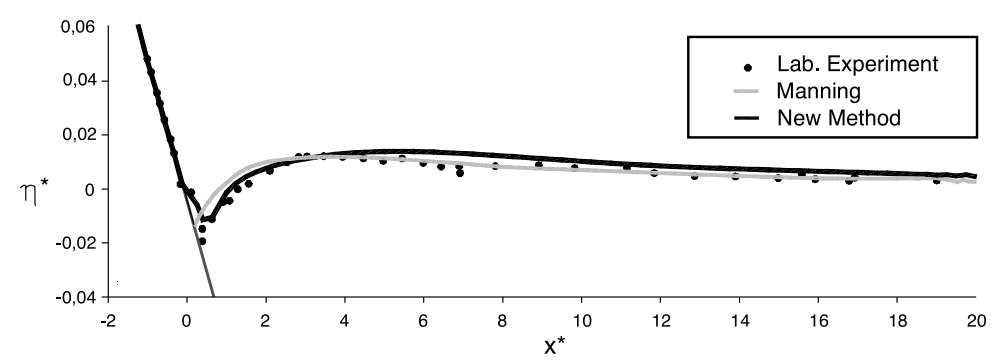

(c) $t^{*}=65$

Fig. 5. Free surface comparison.

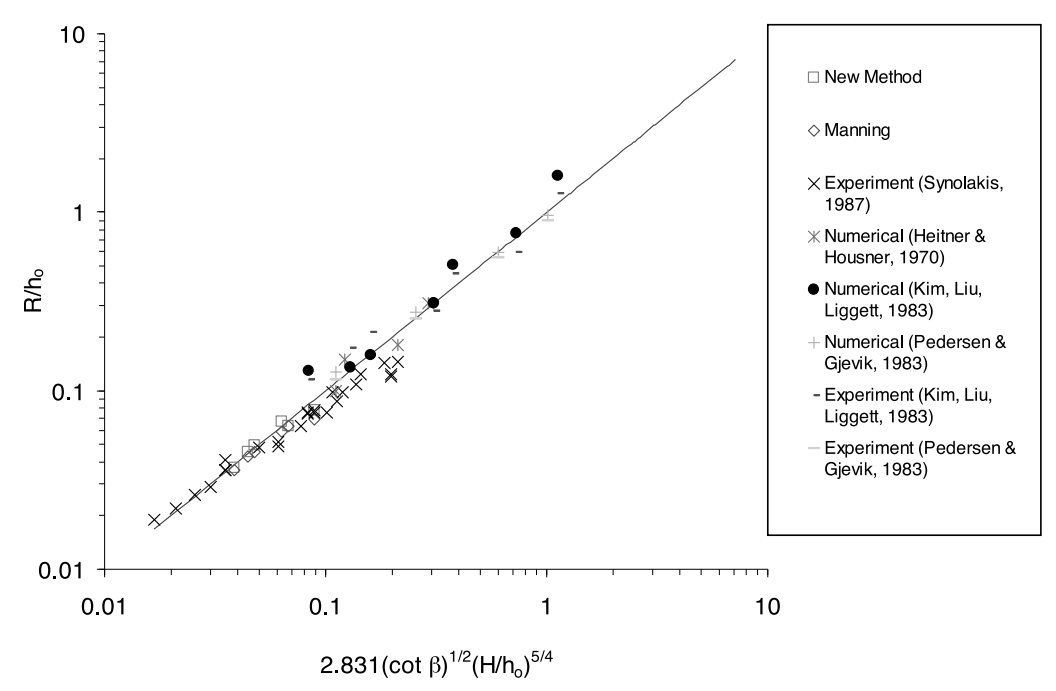

Fig. 6. Run up height.

layer film. The measured velocity data is used to calculate the pressure gradient which is applied as the model input. The simulation is conducted to obtain the bed stress. In this case, a 1D model is used to cover the boundary-layer do- main within a vertical direction. The water depth 0.1 meter above the bed is taken to ensure that the pressure gradient is applied outside the boundary layer. The vertical grid size is 0.0004 meter. The simulation is conducted with a time step 
Table 1. Run-up height.

\begin{tabular}{c|c|c|c|c|c}
\hline & \multicolumn{3}{|c|}{$R / h_{\mathrm{o}}$} & \multicolumn{2}{c}{ Square error } \\
\hline Cot $\phi$ & $\begin{array}{c}\text { Eq. (19) } \\
(1)\end{array}$ & $\begin{array}{c}\text { MM } \\
(2)\end{array}$ & $\begin{array}{c}\text { NM } \\
(3)\end{array}$ & $\begin{array}{c}\text { MM } \\
((1)-(2))^{2}\end{array}$ & $\begin{array}{c}\text { NM } \\
((1)-(3))^{2}\end{array}$ \\
\hline 19.85 & 0.089 & 0.069 & 0.078 & 0.000407 & 0.000116 \\
\hline 11.43 & 0.068 & 0.064 & 0.063 & 0.000016 & 0.000017 \\
\hline 10.00 & 0.063 & 0.059 & 0.067 & 0.000017 & 0.000015 \\
\hline 5.67 & 0.048 & 0.045 & 0.050 & 0.000004 & 0.000004 \\
\hline 5.00 & 0.045 & 0.043 & 0.046 & 0.000002 & 0.000001 \\
\hline 3.73 & 0.039 & 0.036 & 0.037 & 0.000008 & 0.000003 \\
\hline \multicolumn{7}{|c|}{ RMSE } & 0.008704 & 0.005404 \\
\hline
\end{tabular}

$\mathrm{MM}=$ Manning Method; NM = New Method.

of 0.001 second for 25 seconds. The bed shear stress measurement and the simulation result is shown in Fig. 3. The simulation shows a good comparison with the measurement data. Similar behaviour is also observed between the data and simulation result.

\subsection{SWE model verification}

The developed method is verified for the case of run-up of a non-breaking wave from a previous study by Synolakis (1987). The run-up occurs due to a solitary wave on a sloping beach and is commonly known as a canonical problem. Two types of model are simulated for this scenario. The first one is the SWE model using the conventional Manning method. The Manning roughness value $(n)$ for the simulation was determined by trial and error. A Manning value of (n) 0.043 was found to provide the best results. The second model is the upgraded SWE model using the new method proposed in this study. The model setup for this case is shown in Fig. 4.

The following non-dimensional variables are introduced:

$$
\begin{gathered}
x^{*}=x / h_{o}, \\
h^{*}=h / h_{o}, \\
\eta^{*}=\eta / h_{o}, \\
t^{*}=t\left(g / h_{o}\right)^{0.5}, \\
U^{*}=U / U_{c}, \\
\tau_{o}^{*}=\tau_{o} /\left(\rho U_{c}^{2}\right),
\end{gathered}
$$

where $h_{o}$ is the initial water depth, $\eta$ is the water elevation, $x$ is the coordinate as shown in the model sketch. An asterisk denotes the corresponding parameter in non-dimensional form. $U_{c}$ is given as

$$
U_{c}=\left(g / h_{0}\right)^{0.5} H
$$

The grid size in the $x$ direction for both models is $0.1 x^{*}$. The time step for both models is $0.001 t^{*}$. It should be noted here that the Manning method is able to provide an accurate result using a time step of $0.1 t^{*}$. However, the new method requires a much finer time step due to the finer grid in the vertical direction. The grid size in the vertical direction is $0.0005 \mathrm{~m}$. In the experiment, the ratio of the initial wave height to the depth is 0.019 with a beach slope of $1: 19.85$.
The incoming solitary wave Reynolds number $\left(R_{E}\right)$ is 1600 , which can be calculated with the following equation:

$$
R_{E}=\frac{U_{c} a_{m}}{v},
$$

where $U_{c}$ is the maximum of the free stream velocity, $a_{m}$ is half of the stroke of water particle displacement. The Reynolds number was found to be much smaller than the transition Reynolds numbers $\left(2 \times 10^{5}<R_{E}<5 \times 10^{5}\right)$ as proposed by Sumer et al. (2010). Thus, the incoming wave is considered a laminar condition.

The initial profile and velocity of the solitary wave is taken as the model initial conditions for the canonical problem of Synolakis (1987), according to the following equations:

$$
\begin{gathered}
\eta(x, 0)=H \times \operatorname{sech}^{2}\left(\sqrt{\frac{3 H}{4 h_{o}^{3}}}\left(x-X_{1}\right)\right) \\
U(x, 0)=\frac{c \eta}{1+\eta} \\
c=\sqrt{g\left(H+h_{0}\right)} .
\end{gathered}
$$

The wave profile is given by Eq. (20) with an initial velocity as given from Eqs. (21) and (22). The location of this initial wave peak is at $X_{1}$ which is situated at half of the initial wave length $(L / 2)$ from the initial slope $\left(X_{0}\right)$. The wave length $(L)$ can be calculated with the following equation:

$$
L=\frac{2}{\sqrt{3 H / 4 h_{o}^{3}}}\left[\operatorname{arccosh}\left(\sqrt{\frac{1}{0.05}}\right)\right] .
$$

The new method is applied to a grid with a water depth higher than $1.2 \mathrm{~cm}$. If the water depth is lower than $1.2 \mathrm{~cm}$, the bed stress is calculated from the momentum equation.

Comparisons of the wave profile at different times, for the Synolakis (1987) laboratory data, the Manning method, and the new method, are shown in Fig. 5. The calculated results using the new method are shown to compare better with the laboratory data than the results using the Manning method. The model was further verified by simulating the same wave with different slope configurations.

The run-up height can be calculated using the following equation, as calculated by Synolakis (1987), as an exact 


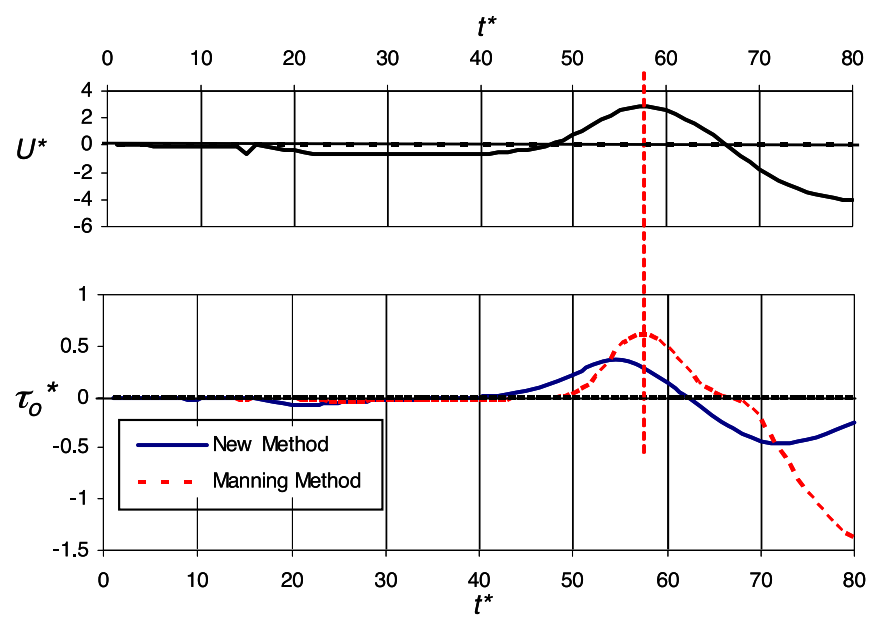

(a) $x^{*}=2$

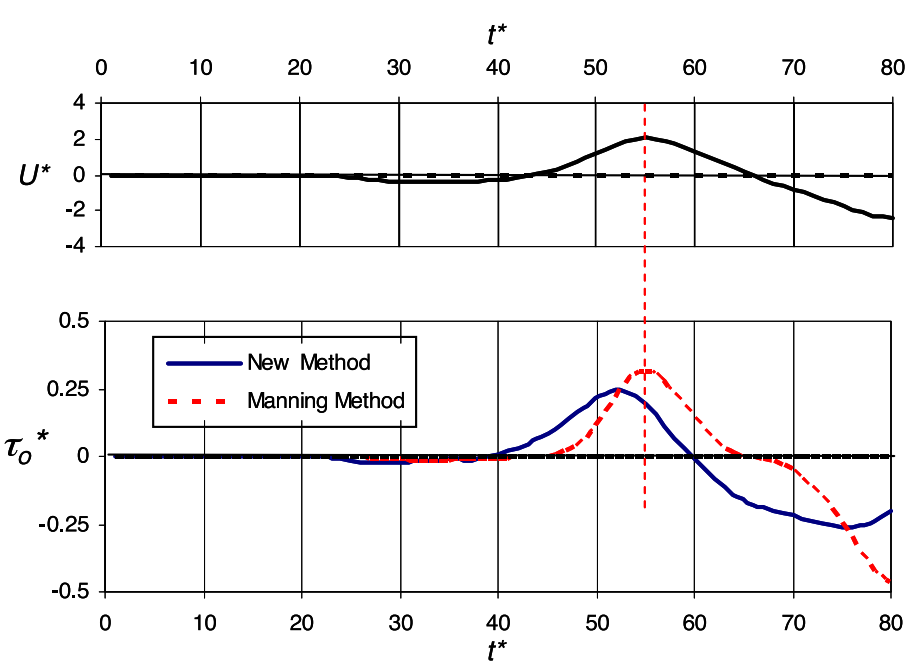

(b) $x^{*}=8$

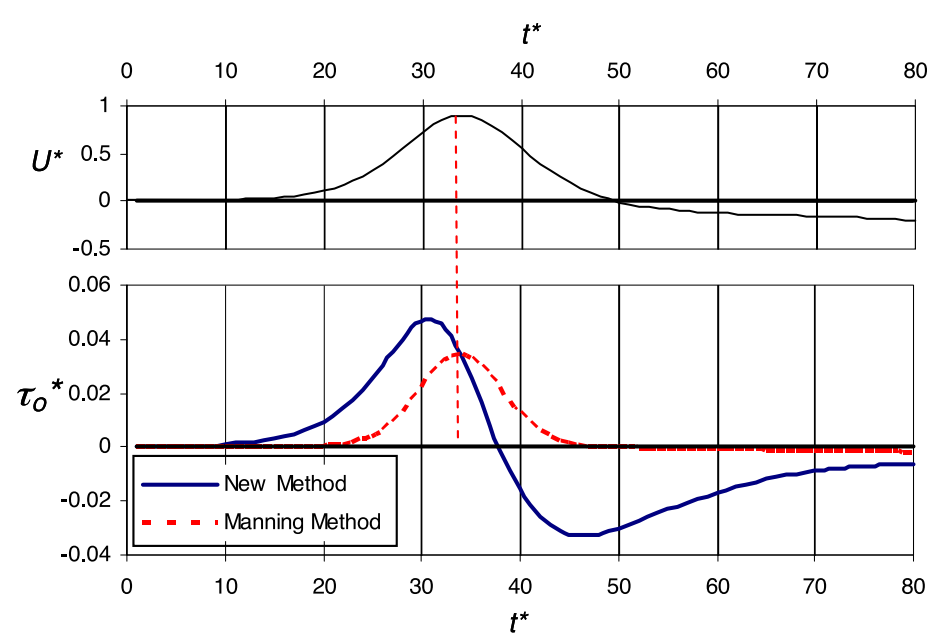

(c) $x^{*}=20$

Fig. 7. Bed stress comparison.

solution of the nonlinear SWE, and is referred to as the runup law:

$$
\frac{R}{h_{o}}=2.831(\cot \phi)^{1 / 2} \times\left(\frac{H}{h_{o}}\right)^{5 / 4}
$$

where $R$ is the estimated run-up height and $\phi$ is the bed slope.

In Fig. 6, computed run-up heights are compared with various laboratory, and earlier numerical, results, normalized as per the run-up law. Run-up height predictions using 


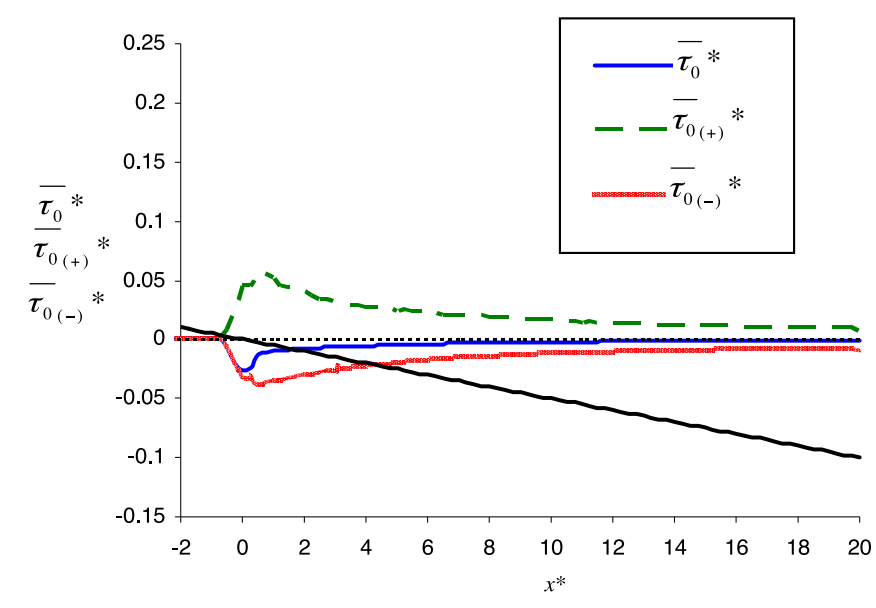

Fig. 8. Bed stress accumulation (New method).

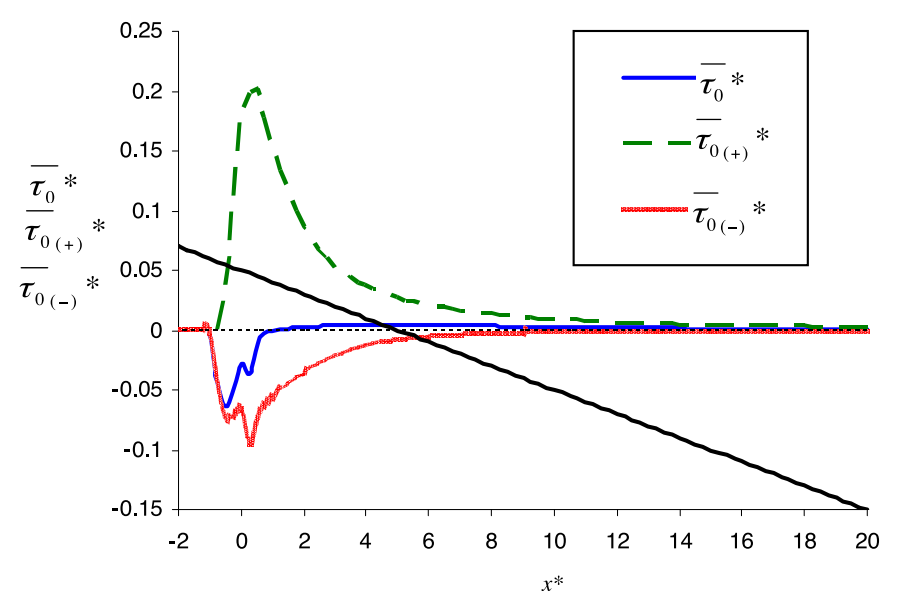

Fig. 9. Bed stress accumulation (Manning method).

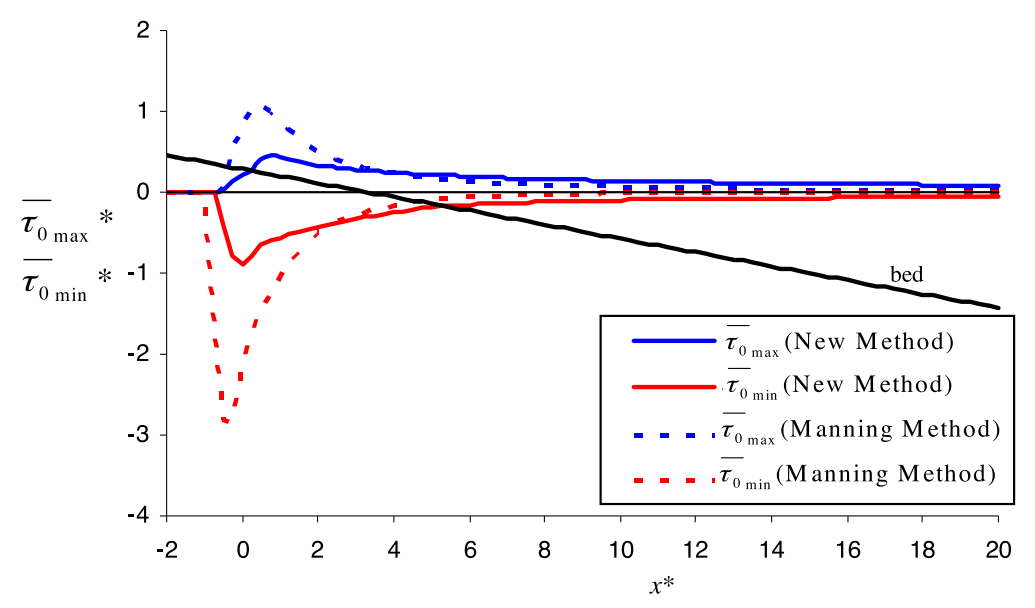

Fig. 10. Maximum and minimum bed stress.

the new method are shown to agree better with the run-up law and laboratory data than earlier results. Results are also listed in Table 1. The major advantage of the new method is its ability to assess the bed stress from the boundary layer.

\section{Bed Stress Assessment}

Further analyses regarding the bed stress are now discussed. The Manning method estimates the bed stress as a function of the square of the average velocity per cubic root of depth, as shown in Eq. (3). This relation often leads to computational errors for very small water depths. The Manning method tends to estimate a lower magnitude in 
deeper water depth and a higher magnitude in a more shallow depth, as shown in Fig. 7. The effect of wave motion on bed stress behavior was found in computation results from the new method. The bed stress peak from the method is not in phase with the free stream velocity. Furthermore, the bed shear stress changes sign during deceleration. The Manning method fails to account for the sign change, because it is based on the square of the velocity; as discussed earlier, it was developed for steady riverine flows.

Next, an analysis of bed stress accumulation is conducted in order to better understand the bed stress behavior during a long wave run up. The following non-dimensional parameters are introduced:

$$
\begin{gathered}
\overline{\tau_{0(-)}^{*}}=\frac{\int_{t_{(-)}=1}^{T_{(-)}} \tau_{0}^{*}(t)_{(-)} d t_{(-)}}{T_{(-)}-t_{(-)}} \\
\overline{\tau_{0(+)}^{*}}=\frac{\int_{t_{+}=1}^{T_{+}} \tau_{0}^{*}(t)_{(+)} d t_{(+)}}{T_{(+)}-t_{(+)}} \\
\overline{\tau_{0}^{*}}=\frac{\int_{t=1}^{T} \tau_{0}^{*}(t) d t}{T-t},
\end{gathered}
$$

where ${\overline{\tau_{0}^{*}}}_{(-)}$is the average value of negative nondimensional bed stress, $\overline{\tau_{o}^{*}}$ is the average value of positive non-dimensional bed stress, $\overline{\tau_{o}^{*}}$ is the total average non-dimensional bed stress, $\tau_{o}^{*}(t)$ is the calculated nondimensional bed stress at time $t$, with $\tau_{o}^{*}(t)_{(-)}$and $\tau_{o}^{*}(t)_{(+)}$ corresponding to negative and positive bed stress values, respectively. $T$ is the simulation time, with $T_{(+)}$and $T_{(-)}$corresponding to the period length of positive and negative bed stress, respectively. $t$ is the corresponding time of the calculated bed stress, with $t_{(+)}$and $t_{(-)}$denoting the time where the bed stress is positive and negative, respectively. Negative and positive signs denotes the direction towards, or leaving, the shoreline, respectively. The maximum $\left(\tau_{o(\max )}^{*}\right)$ and minimum $\left(\tau_{o(\min )}^{*}\right)$ value of non-dimensional bed stress is also investigated.

For a periodic wave motion, it is expected that the sediment transport moves onshore and offshore leaving the beach at equilibrium. However, it was found that this does not apply to the case of a long solitary wave run-up. Overall, both methods show a similar trend. Analysis of bed stress accumulation for both methods (Figs. 8 and 9) shows that a total average bed stress with a negative value (i.e., directed offshore, as during run-down) is more dominant than a total average bed stress with a positive value (i.e., directed to shore, as during run-up).

It is also observed that the average positive only value is higher than the average negative only value, which corresponds to the shorter period of run-up, and the longer period of run-down. Figure 10 compares the extreme values (minimum and maximum) for the bed stress determined by the two different methods, and sediment transport moving towards the shoreline is shown to occur in a shorter period compared to sediment transport leaving the shoreline.

\section{Conclusion}

An assessment of the bed shear stress under a solitary wave run-up was carried out in this study, using the conventional Manning method, and a new method based on the $k-\omega$ equations. Both methods were used to simulate the evolution of solitary waves for the canonical problem of Synolakis (1987) for a non-breaking wave condition, with satisfactory results. Comparisons of run-up heights and detailed free surface profiles particular at the moving shoreline, show that the new method exhibits smaller deviations, compared with laboratory measurements, than the Manning method. This is perhaps to be expected, since the Manning method was developed for steady unidirectional flows, and cannot reproduce well the bed stress under a wave motion, except with ad-hoc assumptions. The Manning method fails to explain the phase shift of the velocity peak to the bed stress. It also fails to predict the change of sign during the deceleration phase in the solitary wave profile. The method proposed in this study is able to assess bed stress behavior under wave motion. Bed stress comparisons between the Manning method and the new method shows that the Manning method tends to higher magnitudes in a shallow area and lower magnitudes in deeper areas. Further analysis of bed stress accumulation shows that the bed stress away from the shoreline will be more dominant during the entire runup process.

Acknowledgments. This research was supported by Grant-inAid for Scientific Research from the Japan Society for the Promotion of Science (No. 22360193), and partially supported by the Open Fund for Scientific Research from the State Key Laboratory of Hydraulics and Mountain River Engineering, Sichuan University, China. The first author is a scholarship holder under the auspices of the Indonesian Ministry of Education. The authors would also like to thank Professor Synolakis and an anonymous reviewer for their constructive review of the present paper.

\section{References}

Adityawan, M. B., 2D modeling of overland flow due to tsunami wave propagation, Masters Thesis, Institut Teknologi Bandung, Indonesia, 2007.

Adityawan, M. B., H. Tanaka, and Suntoyo, Characteristic of turbulent boundary layer under skew wave, Proc. 3rd International Conference on Estuaries and Coasts, 281-288, 2009.

Boussinesq, J., Théorie des ondes et des remous qui se propagent le long d'un canal rectangulaire horizontal, en communiquant au liquide contenu dans ce canal des vitesses sensiblement pareilles de la surface au fond, Journal de Mathématique Pures et Appliquées, 17, 55-108, 1872.

Elfrink, B. and J. Fredsøe, The effect of the turbulent boundary layer on wave run up, Prog. Rep., 74, 51-65, 1993.

Geist, E. L., V. V. Titov, and C. E. Synolakis, Tsunami: Wave of change, Sci. Am., 294, 56-63, 2006.

Hansen, W., Hydrodynamical methods applied to oceanographic problems, Proc. Symp. Math.-hydrodyn. Meth. Phys. Oceanogr., 1962.

Heitner, K. L. and G. W. Housner, Numerical model for tsunami run-up, Proc. ASCE WW3, 701-719, 1970.

Isobe, M., S. Takahashi, S. P. Yu, T. Sakakiyama, K. Fujima, K. Kawasaki, Q. Jiang, M. Akiyama, and H. Oyama, Interim development of a numerical wave flume for maritime structure design, Proc. Civil Eng. Ocean, 15, 321-326, 1999.

Kabiling, B. and S. Sato, Two-dimensional nonlinear dispersive wavecurrent model and three-dimensional beach deformation model, Coast. Eng. Jpn., 36, 195-212, 1993.

Kim, S. K., P. L.-F. Liu, and J. A. Liggett, Boundary integral equations for solitary wave generation propagation and run-up, Coast. Eng., 7, 299317, 1983.

Kusuma, M., M. B. Adityawan, and M. Farid, Modeling two dimension 
inundation flow generated by tsunami propagation in banda aceh city, Proceedings of International Conference on Earthquake Engineering and Disaster Mitigation, 2008.

Lin, P., K.-A. Chang, and P. L.-F. Liu, Runup and rundown of solitary waves on sloping beaches, J. Waterway Port Coast. Ocean Eng., 125(5), 247-255, 1999.

Liu, P. L.-F., C. E. Synolakis, and H. Yeh, Impressions from the first international workshop on long wave runup, J. Fluid Mech., 229, 675688,1991

Liu, P. L.-F., T.-R. Wu, F. Raichlen, C. E. Synolakis, and J. Borrero, Runup and rundown generated by three-dimensional sliding masses, J. Fluid Mech., 536, 107-144, 2005.

Liu, P. L.-F., Y. S. Park, and E. A. Cowen, Boundary layer flow and bed shear stress under a solitary wave, J. Fluid Mech., 135, 449-463, 2007.

Lynett, P. J., J. C. Borrero, P. L.-F. Liu, and C. E. Synolakis, Field survey and numerical simulations: a review of the 1998 papua new guinea earthquake and tsunami, Pure Appl. Geophys., 160(11), 2119-2146, 2003.

Madsen, P. A. and O. R. Sørensen, A new form of the Boussinesq equations with improved linear dispersion characteristics. Part 2. A slowly-varying bathymetry, Coast. Eng., 18, 183-204, 1992.

Nielsen, P., Shear stress and sediment transport calculations for swash zone modeling, Coast. Eng., 45, 53-60, 2002.

Nwogu, O., An alternative form of the Boussinesq equations for nearshore wave propagation, J. Waterway Port Coast. Ocean Eng., 119(6), 618638, 1993.

Pedersen, G. and B. Gjevik, Run-up of solitary waves, J. Fluid Mech., 135(3), 283-290, 1983.

Peregrine, D. H., Long wave on a beach, J. Fluid Mech., 27, 815-827, 1967.

Sumer, B. M., P. M. Jensen, L. B. Sørensen, J. Fredsøe, P. L.-F. Liu, and S. Cartesen, Coherent structures in wave boundary layers. Part2. Solitary motion, J. Fluid Mech., 646, 207-231, 2010.
Suntoyo, Study on turbulent bottom boundary layer under non-linear waves and its application to sediment transport, Ph.D. Dissertation, Tohoku University, Japan, 2006.

Suntoyo, H. Tanaka, and A. Sana, Characteristics of turbulent boundary layers over a rough bed under saw-tooth waves and its application to sediment transport, Coast. Eng., 55(12), 1102-1112, 2008.

Synolakis, C. E., The runup of solitary waves, J. Fluid Mech., 185, 523$545,1987$.

Tanaka, H., Bed load transport due to non-linear wave motion, Proc. of 21st Int. Conf. Coast. Eng., 1803-1817, 1988.

Tanaka, H. and A. Thu, Full-range equation of friction coefficient and phase difference in a wave-current boundary layer, Coast. Eng., 22, 237-254, 1994.

Tanaka, H., B. M. Sumer, and C. Lodahl, Theoretical and experimental investigation on laminar boundary layers under cnoidal wave motion, Coast. Eng. J. Jpn., 40(1), 81-99, 1998.

Titov, V. V. and C. E. Synolakis, Numerical modeling of tidal wave runup, J. Waterways Port Coast. Ocean Eng., 124(4), 157-171, 1998.

Tsuji, Y., S. Matsutomi, F. Imamura, and C. E. Synolakis, Field survey of the east java earthquake and tsunami, Pure Appl. Geophys., 144(3/4), 839-855, 1995.

Vittori, G. and P. Blondeaux, Turbulent boundary layer under solitary wave, J. Fluid Mech., 615, 433-443, 2008.

Wang, G. Q., F. Liu, X. D. Fu, and T. J. Li, Simulation of dam breach development for emergency treatment of the Tangjiashan Quake Lake in China, Sci. China Ser. E: Tech. Sci., 51, 82-94, 2008.

Wei, G. and J. T. Kirby, A time-dependent numerical code for extended Boussinesq equations, J. Waterway Port Coast. Ocean Eng., 120, 251$261,1995$.

M. B. Adityawan (e-mail: bagus@kasen1.civil.tohoku.ac.jp) and H. Tanaka 